\title{
Postgraduate Studies: The Challenges of Research and Thesis Writing
}

\section{Uduak Imo Ekpoh}

\author{
Department of Educational, Administration and Planning, University of Calabar, Calabar, Nigeria
}

Email: druduakekpoh@yahoo.com

\section{Doi:10.5901/jesr.2016.v6n3p67}

\begin{abstract}
The study considered postgraduate studies through an examination of the challenges of research and thesis writing in the University of Calabar, Calabar, Nigeria. A survey research design was adopted for the study and a sample of 200 postgraduate students comprising Master's and Doctoral candidates who wrote their theses during the 2011/2012 academic session, were used. Four research questions guided the study. A questionnaire tagged "Postgraduate Studies Questionnaire" (PGSQ) was developed, validated and used for data collection. The reliability estimate of the instrument using Cronbach Alpha was 0.86. Data collected were analyzed using frequencies and percentages. Findings indicated that postgraduate students at the University of Calabar experienced a variety of challenges in research and thesis writing aspects of their training. The most critical of the challenges revolved around students and institutional-related factors. However, supervisor-related factors did not pose any significant challenges to postgraduate students. Suggestions made by postgraduate students on ways of improving their research and thesis writing were that core research areas should be emphasized and taught in departmental seminars and workshops and internet facilities should be provided for students. Based on the findings of the study, it was recommended that periodic progress report on each postgraduate student should be submitted every semester as a feedback mechanism for monitoring progress. This will enhance proper tracking to ensure students completion on schedule.
\end{abstract}

Keywords: Postgraduate studies, Challenges, Research, Thesis writing.

\section{Introduction}

Demand for postgraduate education in Nigeria has escalated since the year 2000 and is still growing. This growth in demand to higher education is not limited to Nigeria but to both developing and developed countries of the world (Kaur \& Sidhu, 2009). Among the factors highlighted in the escalating demand are: lack of immediate employment after first degree, the desire to acquire higher degree or to achieve individual academic goals and achieve personal independence. Other reasons as pointed out by Etejere (2006) are economic motivation and high demand for specialized skills by the public and private sectors. Postgraduate education is the higher level of education which is provided after bachelor's degree. It is formal and comprised of structured programmes. It exists in three levels of Postgraduate Diploma or certificate, Master's degree and Doctor of Philosophy (Ph.D) degree. The provision of postgraduate education takes the form of course work or a combination of course work and thesis writing. In the later case, students offer courses to satisfy course work requirements before embarking upon research and thesis writing. The research and thesis writing are critical components of postgraduate studies. Postgraduate research students work with their supervisors on their theses. The main duty of the supervisor is to provide guidance to students by checking every aspect of their work and also making inputs and comments where necessary. These postgraduate programmes are either organized on full-time or part-time basis.

Much as there has been an escalating demand for postgraduate admission, the yearly out-put of graduating students has continued to decline. There is a noticeable mismatch between graduate students intake and the number of higher degree graduate output. Previous researches have observed that up to half of the students who begin their graduate studies spend more than the required number of years and some do not complete their studies at all (Golde, 2001; Duze, 2010). For instance, an analysis of progress report of Masters and Ph.D students in some selected departments during the 2005/2006 academic session in University of Calabar indicated the following: out of the 43 Masters students who were enrolled during the period only 6(14\%) completed their programme on schedule, while $37(86 \%)$ were at various stages of their research by the year $2010 / 2011$ academic session. Similarly during the same period only 8(16\%) Ph.D students out of 50 completed their studies on schedule. Four(8\%) students had to withdraw for various reasons, while $38(76 \%$ ) could not complete by the end of 2010/2011 session. Postgraduate students in Nigerian Universities encounter many difficulties which unduly prolong the successful completion of their programmes. In the 
course of postgraduate studies, the challenges encountered by part-time students are often different from those experienced by full-time students, apparently because in most cases, part-time students may be in full-time employment or have other responsibilities and commitments which distract their focus.

Graduate students in the University of Calabar come from varied and diverse background in terms of age, experience, ability, marital status and so on. Some have funding or scholarship support while some are self financing. Some are workers which present the problem of divided interest and low commitment. These background factors inadvertently affect students' ability and achievement. Students offering graduate studies at the University of Calabar are also under increased pressure to complete their programmes within a specified time period. For the Masters degree programme, full-time students have a minimum completion period of three semesters and a maximum of five semesters, while the Ph.D programme have a duration of six semesters for full-time students and a maximum of ten semesters. In terms of the part-time students, the minimum programme duration for Ph.D students is 10 semesters and a maximum of 14 semesters, while for the masters programme the duration is four semesters minimum and six semesters maximum.

The most challenging problem encountered by graduate students in the course of their study is the postgraduate research and thesis writing. Most graduate students after completion of course work spend more time on their research work. Postgraduate research revolves around two key people: the student and the supervisor. Lessing and Schulze (2003) observed that successful completion of thesis by students is due to a combination of factors such as the intelligence, the training received and perseverance of the students, as well as, proper guidance by the research supervisor. Smith, Brownell, Simpson and Deshler (1993:53) opined that "a successful dissertation experience occurs only through significant efforts by both the adviser and the student." Equally, Duze (2010) noted that postgraduate education in Nigeria is bedeviled with all sorts of problems, ranging from personal, psychological problems to system or procedural problems. This research is specifically conducted to unravel the challenges encountered by postgraduate students in their research or thesis writing in University of Calabar, Nigeria.

\section{Literature Review}

Earlier studies have shown that a significant number of graduate students fail to complete their programmes due to various challenges. For instance Ismail, Abidden and Hassan (2011) noted that students experience challenges during their research process. Some of the identified challenges include not being familiar with research process, difficulties in topic selection and lack of knowledge about research methodology. Sometimes students problems could be personal or family difficulties, financial pressure and problems associated with employment.

Duze (2010) undertook an analysis of problems encountered by postgraduate students in Nigerian universities. The result showed that the most highly identified problem areas were in the order given as follows: (1) problem of lack of equipment; (2) academic problem; (3) financial problem; (4) problem of data collection; (5) problem of supervision; (6) problems related to university administration; (7) accommodation problem; (8) family background; (9) external examiner's problem and (10) personal problems. Igun (2010) in a study on difficulties experienced by postgraduate students in some Nigerian universities found that majority of respondents were encountering challenges. The most commonly cited problem was that of elongated durations caused by strike action. This was followed by lack of research materials and research topic challenges. In the study more than one-third of respondents (35\% of respondents) had problems in selecting good topics as well as having access to research materials. Seventy percent (70\%) had difficulties in research interaction, well over half of the respondents identified institutional factors as having the most negative effect on them. Also, a study by Hofman and Berg (2000) reported that lack of funding was seriously affecting students conduct of their research.

In a study on postgraduate supervision, Lessing and Schulze (2003) observed that students' aspirations were not often met in most aspects of supervision. In another study, Golde and Dore (2001) explored the experiences of Ph.D students and found that more than forty percent of the postgraduate students reported that they would pick a different topic if they could start all over again, while thirty six percent stated that they would chose a different supervisor if they were given the opportunity to do so, and about a third of the respondents said that they would select another field of study if they had to re-do their postgraduate studies. Kearsley (1998) argued that students were not getting enough time with their supervisors because the supervisors were overworked and there was acute shortage of qualified supervisors. Another dimension noted by Lubbe, Worral and Klopper (2005) was that senior faculty members were under increasing pressure to teach, publish and to attract income to their universities.

Helm (1989) noted that the problems which prevent graduate students from completing studies are three fold and mostly revolve around research design, data collection and processing and writing of the research report. These 
problems as observed by Mouton (2001) could be caused by student's inexperience, poor supervision or an inefficient system.

Spear (2000) found in his research that common complaints from students concerned irregular contact with supervisors who most of the time are preoccupied with teaching or administrative duties, have too many supervisees or have to be away from the University frequently for external examination or conferences. Lovitts and Nelson (2000) carried out a review of factors affecting graduate students non-persistence in graduate studies. The factors were categorized into climate and fit, type of financial assistance, unsuitable programmes and faculty roles. With regards to climate and fit, the researchers found that problem usually start with the application process. Their findings indicated an academic ignorance on the part of the students as well as the quality, goals, nature, strengths and reputation of the graduate programme itself. They discovered that financial assistance was important for students, but that it did not guarantee students' success.

Another major obstacle to postgraduate research is the lack of institutional infrastructure. Achimuju, Oluwagbemi and Oluwarati reported in their studies that tertiary institutions in Nigeria lacked Information and Communication Technology (ICT) infrastructure, noting that the basic software for research were not available and where they were available they were not accessible.

Though much research have been carried out on challenges or problems of research/thesis writing by postgraduate students elsewhere, but none to the researchers knowledge has been done in the University of Calabar. The present study addresses postgraduate studies and the challenges of research and thesis writing from "tridimensional or triadic perspective which includes student-related, supervisor-related and institutional- related challenges.

\section{Statement of the Problem}

Over the last decade, there has been a general growth in enrollment and interest in graduate studies in Nigerian universities. Prior to now, graduate study was a preserve of very few knowledgeable persons in their subject areas. Now, there is widespread perception that anyone can do it. Graduate studies involve course work and research. The research is done after the completion of course work. A student is expected to be guided by the supervisor in writing the research. A supervisor has a major role to play in mentoring and providing the intellectual support in thesis writing. It is however observed that graduate students tend to spend more years pursuing their research programmes than the required maximum period. This has created additional problem of overburdening the supervisors with more students than they can cope, overstretching of existing facilities and problem of funding on the part of the student. There is the added pressure on students to write quality thesis and also finish their programmes within specified time frame or their admission will lapse. At this point, it is pertinent to pose the question, "what are the challenges faced by graduate students in research and thesis writing"? This study is therefore designed to provide answer to this question.

\section{Purpose of the Study}

The following specific objectives guided the study:

1. To determine the reasons for students' pursuit of postgraduate studies.

2. To ascertain if postgraduate students encounter challenges in the pursuit of their degrees.

3. To ascertain if the challenges encountered by postgraduate students are due to supervisor-related, studentsrelated or institutional-related factors.

4. To find out possible ways in which the challenges can be solved.

\section{Research Questions}

In line with the objectives of this study, the following research questions guided the study:

1. What reasons account for students' pursuit of post graduate studies ?

2. Do graduate students encounter challenges in the pursuit of their degrees?

3. What are the challenges to postgraduate students' research in terms of supervisor- related, students- related and institutional-related factors?

4. In what ways can the challenges to postgraduate research be solved? 


\section{Methods}

The present study, which is a survey design was carried out at the University of Calabar (Unical), Calabar, Cross River State, Nigeria. University of Calabar was selected because it offers a diversity of programmes at the graduate level. The study was conducted during the 2011/2012 academic session. The participants in this study were 200 postgraduate students drawn from different faculties across the University.

Purposive sampling technique was adopted to accommodate a wide range of participants across the faculties. Besides, the focus was mainly on those students who were writing their thesis. The sample was made up of $80(40 \%)$ males and 120(60\%) females. Similarly, 128(64\%) were masters degree students while, 72(36\%) were doctoral degree students. Further break down of the sample showed that $28(14 \%)$ were on scholarship while a significant majority $172(86 \%)$ were self sponsored. A great majority of the respondents $160(80 \%)$ were undertaking their postgraduate studies on full-time basis while 40(20\%) of them were part-time students.

An instrument titled "Postgraduate Studies Questionnaire (PGSQ)" was used for data collection. The questionnaire was developed after a careful review of literature. The instrument consisted of both open and close ended response items in order to get more information and to encourage the respondents to offer useful details. Section A of the instrument was on background data which was designed to provide detailed information about participants, covering such areas as gender, age, marital status, higher degree in view, year of study, current status, funding sources and reasons for pursuing post graduate studies.

Section B was on challenges encountered by postgraduate students in research and thesis writing. This was subdivided into three sections: supervisor-related (10 items), students- related( 10 items) and institutional- related( 10 items). The items were measured on a four-point rating scale of the agreement with existence of challenge, and the response options were Not Challenging (NC), Somewhat Challenging (SC), Challenging (C) and Very Challenging (VC). Section C was for the students to offer their own suggestions on what should be done to improve postgraduate research.

The instrument was given to two experts in Tests and Measurements to ascertain its face validity. The reliability of section B of the instrument was determined using Cronbach Alpha reliability method and the index was 0.86 . Hence the instrument was considered adequate for the study objectives. The questionnaire was administered personally by the researcher with the help of trained research assistants. All the 200 copies of the questionnaire were successfully retrieved. Data generated from the questionnaire were analyzed using frequencies and percentages.

\section{Results and Discussion}

The result and discussion were based on the four research questions posed for the study.

\subsection{Research Question 1}

What reasons account for students' pursuit of post graduate studies?

To answer this research question, data gathered were analyzed using frequency count and percentages. The result of the analysis is presented in Table 1.

Table 1: Reasons for postgraduate studies

\begin{tabular}{lccc}
\hline Reasons & Frequency & Percentage & Rank \\
\hline Better employment prospect & 60 & $30 \%$ & $1^{\text {st }}$ \\
To upgrade qualification & 52 & $26 \%$ & $2^{\text {nd }}$ \\
Pursuit of knowledge & 48 & $24 \%$ & $3^{\text {rd }}$ \\
Personal fulfillment & 24 & $12 \%$ & $4^{\text {th }}$ \\
Lack of employment & 16 & $8 \%$ & $5^{\text {th }}$ \\
\hline
\end{tabular}

Results in Table 1 show that better employment prospect had the highest percentage of $30 \%$ and ranked first as the major reason for students pursuance of postgraduate studies. This was followed by the desire to upgrade qualification, $26 \%$ and the desire to acquire knowledge $24 \%$. Personal fulfillment came fourth with $12 \%$ and lack of employment was ranked last with $8 \%$.

The fact that $30 \%$ of the respondents ranked better employment prospect as reason for pursuit of postgraduate study confirms an earlier study by Kaur and Sidhu (2009) which found that the increasing demand by students for 
postgraduate education is in their realization of the role of postgraduate education in enhancing their career prospects. Ordinarily, one would have expected the pursuit of knowledge and personal fulfillment to rank top, which unfortunately ranked low among students. The possible explanation for this finding may hinge on the fact that there is a general high cost of living which has made it impossible for individuals within the society to meet their daily expenditure. People are eagerly looking for opportunities that will give them better employment with enhanced income. Furthermore, graduate studies in the past use to be the preserve of intelligent and outstanding scholars, but presently, it is an all comers affair due to various reasons as observed in this study.

\subsection{Research Question 2}

Do graduate students encounter challenges in the pursuit of their degrees?

The answers provided by the respondents on the issue of challenges is presented in Table 2.

Table 2: Percentage of post graduate students who encounter challenges

\begin{tabular}{ccc}
\hline Response & Frequency & Percentage \\
\hline Yes & 184 & $92 \%$ \\
No & 16 & $8 \%$ \\
\hline
\end{tabular}

Postgraduate students in this study were asked if they encountered challenges in the pursuit of postgraduate studies and research. Surprising, about 184( 92\%) indicated that they experienced challenges in their research and thesis writing, while an insignificant proportion of $16(8 \%)$ indicated that they had no challenge. The outcome of this study is in line with the research report of Duze (2010) that people are yet to come across a postgraduate student in a Nigerian university who is not grumbling or complaining about one thing or the other in the system. Similarly, Ismail et al(2011) reported that graduate students often experience challenges which prolong their studies and hinder them from finishing on schedule. The findings of this study is worrisome. The many challenges that graduate students encounter account for the fact that many students who enroll in postgraduate programmes do not always graduate on time. It is rare to find a masters' degree student who graduates within the minimum stipulated period of two years. For the doctoral students, some spend up to seven years before they can graduate because of the challenges they encounter.

\subsection{Research Question 3}

What are the challenges to postgraduate students in research/thesis writing in terms of supervisor-related, studentsrelated and institutional-related factors?

The respondents were asked the challenges they were experiencing in research and thesis writing. Data gathered in answer to this question were analyzed using frequency $(f)$ count and percentages. The respondents were to agree on the extent to which the factors were challenging using the following: Not Challenging (NC); Somewhat Challenging (SC); Challenging(C) and Very Challenging(VC). The result is presented in Table 3.

Table 3: Challenges of postgraduate studies

\begin{tabular}{|c|c|c|c|c|c|}
\hline S/N & Supervisor- related challenges & Nc & Sc & $\mathrm{C}$ & Vc \\
\hline 1 & The supervisor is too busy with extensive commitment & $52(26 \%$ & $76(380$ & $(18 \%)$ & $36(18 \%)$ \\
\hline 2 & Incompatibility with supervisor & $124(62$ & $36(180$ & $(12 \%)$ & $16(8 \%)$ \\
\hline 3 & Supervisor is not up to date in the field & $132(66$ & $32(160$ & $(14 \%)$ & $8(4 \%)$ \\
\hline 4 & The supervisor lacks commitment & $104(52$ & $44(22$ & $(16 \%)$ & $20(10 \%)$ \\
\hline 5 & The supervisor is not always available to devote suffici & $68(34 \%$ & $52(26$ & $(24 \%)$ & $32(16 \%)$ \\
\hline 6 & Supervisor lacks expertise on students topic & $128(64$ & $24(12$ & $(20 \%)$ & $8(4 \%)$ \\
\hline 7 & The supervisor is unduly slow in reading thesis drafts & $88(44 \%$ & $60(30$ & $(18 \%)$ & $16(8 \%)$ \\
\hline & Displays lack of respect for student & $144(72$ & $24(12$ & $(12 \%)$ & $8(4 \%)$ \\
\hline & Lack of proper guidance & $100(50$ & $52(26$ & $(18 \%)$ & $12(6 \%)$ \\
\hline & $\begin{array}{l}\text { Problem of interpersonal relationship } \\
\text { Student- related challenges }\end{array}$ & $116(58$ & $32(16$ & $(18 \%)$ & $16(8 \%)$ \\
\hline & Problem of funding & $44(22 \%$ & $24(12$ & $(14 \%)$ & $104(52 \%)$ \\
\hline & Modality of study which conflicts with employment & $56(28 \%$ & $40(20$ & $(22 \%)$ & $60(30 \%)$ \\
\hline
\end{tabular}


13 Expensive cost of obtaining research materials

14 Lack of access to research materials

15 Difficulties in generating researchable topic

16 Lack of ICT knowledge of research method

17 Insufficient time for research

18 Insufficient knowledge of research method

19 Problem of data collection

20 Lack of commitment to research

Institutional related challenges

21 Non-adherence to calendars

22 Frequent closure due to strike actions

23 Poor library facilities

24 Unnecessary departmental delays

25 Lack of internet study facilities

26 Difficulties in getting approval for research topic

27 Inadequate study facilities e.g

27 Laboratory, resource room

28 Poor social services e.g accommodation

29 Insufficient academic staff

30 Lack of research ambience (atmosphere) in the University.
$20(10 \%) 32(16 \%) 64(32 \%) 84(42 \%)$

$12(6 \%) 52(26 \%) 48(24 \%) 88(44 \%)$

$80(40 \%) 52(26 \%) 48(24 \%) 20(10 \%)$

$80(40 \%) 48(24 \%) 40(20 \%) 32(16 \%)$

$88(44 \%) 60(30 \%) 36(18 \%) 16(8 \%)$

$84(42 \%) 60(30 \%) 24(12 \%) 32(16 \%)$

$20(10 \%) 84(42 \%) 52(26 \%) 44(22 \%)$

$104(52 \%) 44(22 \%) 36(18 \%) 16(8 \%)$

$48(24 \%) 32(16 \%) 32(16 \%) 88(44 \%)$

$20(10 \%) 40(20 \%) 68(34 \%) 72(36 \%)$

$16(8 \%) 44(22 \%) 68(34 \%) 72(36 \%)$

$16(8 \%) 28(14 \%) 64(32 \%) 92(46 \%)$

$24(12 \%) 24(12 \%) 56(28 \%) 96(48 \%)$

60 (30\%) 48 (24\%) 48 (24\%) 44 (22\%)

$12(6 \%) 52(26 \%) 64(32 \%) 72(36 \%)$

$44(22 \%) 36(18 \%) 44(22 \%) 76(38 \%)$

$56(28 \%) 60(30 \%) 48(24 \%) 36(18 \%)$

$20(10 \%) 68(34 \%) 28(14 \%) 84(42 \%)$

Table 3 indicates that the most challenging of the supervisor-related factors was that the supervisors were too busy with extensive commitment to be effective with their roles $(36,18 \%)$. This was closely followed by non-availability of supervisors $(32,16 \%)$. The outcome of this research, however, is in line with an earlier study by Spear (2000) who found that the most common complaint from research students concern irregular contact with supervisors, who most of the time are preoccupied with teaching or administrative duties, have too many supervisees' or have to be away from the university frequently for conferences or external examinations. Similarly, Lubbe, Worrall and Klopper (2005) noted that senior faculty members were being put under increasing pressure to teach, to publish, and to generate income. Quite often, "students' problems" will be down the list of priorities of senior academics. Possibly in response to these observations, Ismail et al (2011) noted that effective supervision is important in guiding student's in their research progress. To this end, Spear (2000) advocated that regular, thoughtful supervision and supervisors availability are critical to successful graduate programme completion. However, the outcome of this finding also shows that supervisorrelated factors such as lack of supervisors commitment (52\%), supervisor not up-to-date in the field(66\%,) incompatibility with supervisor (62\%), lack of expertise on students' topic( 64\%), lack of respect for student (72\%) and interpersonal relationship (58\%) did not pose any challenge to postgraduate students research. Apparent from this finding is the fact that supervisors in the University of Calabar are dedicated and effective in the discharge of their responsibilities with regards to postgraduate students' theses supervision.

In terms of students- related factors, the most challenging of the factors to postgraduate students research are: problem of funding $(52 \%$,) lack of access to research materials (44\%), expensive cost of obtaining research materials (42\%), mode of study which conflicts with employment (30\%) and problem of data collection (22\%). This study finding is in line with the view of Hofman and Berg (2000) that lack of funding seriously affects some students' research and this could result in serious distraction and deep frustration. The students are expected to work within deadlines and to have a planned time table to complete their thesis on time. The fact that $50 \%$ of students admitted that funding was a problem could be explained by the fact that postgraduate programme in University of Calabar is more expensive than undergraduate education which is subsidized by the Federal Government. The fee charges for Master's and Doctoral degree students in University of Calabar is N75,000 and N80,000 respectively. This amount does not however include other Departmental and Faculty dues, cost of academic materials, text books, accommodation and feeding. As noted by Etejere (2006) the cost of obtaining research materials and the intensity of programme constitute a big problem to postgraduate student success. Besides, as seen in this study, $86 \%$ of the students sampled were self sponsored.

Institutional-related factors were seen to be the most challenging to postgraduate students research. Findings of this study in order of priority, indicate the challenges to include lack of internet facilities (48\%), unnecessary departmental delays (46\%), non-adherence to calendars $44 \%$, lack of research ambience (42\%), poor social service, such as accommodations (38\%) and inadequate study facilities (36\%). The findings of this study is in agreement with Igun (2010) who found that a significant number of postgraduate students encountered problems with research and the frequently reported difficulties were the prolonged semester or session and departmental delays. As should be expected, elongated 
semester constitutes a major problem in postgraduate research. This is because most graduate students know only when they are enrolled but not when they will graduate due to strike action by university workers and riot by students which often result in long closures of universities. The study also found the lack of internet facilities as a major problem affecting postgraduate research. This finding is in line with the observation of Achimuju, Oluwagbemi and Oluwarati (2010) who said that tertiary institutions in Nigeria lack adequate Information and Communication Technology (ICT) infrastructure to effectively tap into the opportunities offered by cyberspace and in most cases, the basic software needed for research are not available and where they are available, they are not accessible. It is worthwhile to note that at times where the facilities are available there will be problem of irregular power supply and poor net-work services or failures

\subsection{Research Question 4}

In what ways can the challenges to postgraduate research be solved?

In response to this research question which was an open-ended question regarding suggestion for improvement of postgraduate research, the respondents gave various suggestions. Summary of the suggestions is presented in Table 4:

Table 4: Students suggestions for improved postgraduate research

- Government at all levels and private organizations should adequately provide financial assistance to graduate students which could be in the form of scholarships or research grants.

- Strict adherence to time for graduate studies. Academic calendars should be followed.

- Provision of research libraries facility. Existing research libraries should be updated and research students should be given access to such facilities.

- Improved internet facilities should be made available to research students.

- Unnecessary departmental delays should be done away with.

- More lecturers should be employed to handle research student. As a rule, supervisors should not have more than five research students to supervise in order to reduce workload.

- Core areas in research such as background to the study, literature review and statement of the problem should be emphasized and taught in departmental seminars and workshops.

- Interactive and more cordial relationships should be encouraged between students and their supervisors.

\section{Conclusion}

This study was confined to the perspective of postgraduate students in University of Calabar. Findings from this study have provided insight into the challenges faced by postgraduate students. Based on the results of this study, it can be concluded that postgraduate students in University of Calabat face many challenges that hinder the successful completion of their studies. The most critical of these challenges are student-related and institutional-related factors. However, supervisor-related factors do not posed any significant challenge to postgraduate students. Thus, the needs of postgraduate students should constitute a core aspect of postgraduate programme and proper attention should be given accordingly.

\section{Recommendations}

In view of the findings of this study, the following recommendations are made:

1. Periodic mounting of skill enhancement seminars and workshops on graduate thesis supervision, research methodology and thesis writing for both lecturers and students. This will enhance quality of research and should be built into graduate programmes.

2. Regular standardized procedure for assessing the progress of graduate students' research and thesis writing should be institutionalized.

3. Periodic progress report on each postgraduate student should be submitted every semester as a feedback and tracking tool to enhance students completion at scheduled time. In addition, functional research schedule should be put in place for postgraduate students. 


\section{References}

Achimugu, P., Oluwagbemi, O., \& Oluwaranti, A.. (2010). An evaluation of the impact of information and communication technology diffusion in Nigerian higher educational institutions. Journal of Information and Communication Technology Impact. 10(1), 25-34.

Duze, C. O. (2010). An analysis of problems encountered by postgraduate students in Nigerian Universities. Journal of Social Science, $22(2), 129-137$.

Etejere, P. A. O.(2006 ). Female participation in postgraduate studies in Nigerian universities: Problems and attrition. International Journal of Education Management (IJEM), 4(1), 1-14.

Golde, C. M. \& Dore, T. M. (2001). At cross purposes: What the experiences of today's doctoral students reveal about doctoral education, A survey initiated by the pew charitable trusts.

Golde, C. M. (2001). Questions to ask when thinking about pursuing a Ph.D, http://www.phd.survey.org/advice/advice.htm accessed 14 october 2003.

Hofman, A.\& Berg, M.V.D. (2000). Determinants of study progress: The impact of student, curricular, and contextual factors in study progress in University Education. Higher Education Europe, XXVV (1), 93-110.

Igun, S. E. (2010). Difficulties and motivation of postgraduate students, in selected Nigerian Universities. Library philosophy and practice, retrieved 31/10/2010.www.webpages.uidaho.edu/-mbolin/igun-postgrad.pdf.

Ismail, A., Abiddin, N. Z. \& Hassan, A. (2011). Improving the development of postgraduate research and supervision. International Education Studies, 4 (1) 78-89.

Kaur, S. \& Sidhu G. K. (2009). A qualitative study of postgraduate students' leaving experiences in Malaysia. International Education studies, 2 (3), 47-56.

Kearsley, G. (1998). Doing Doctoral work at a Distance, http://home.sprynet.com/gkearsley/ doctoral.htm accessed 14 October 2003.

Lessing, A. C. \& Schulze S. (2003). Lecturers experience of postgraduate supervision in distance education context. SAJHE/SATHO, 17 (2).

Lovitts, B. \& Nelson, C. (2000). The hidden crisis in graduate education. Attrition from Ph.D programs (Electronic version). Academe online 86 (6), 44. http://www.aaup.org/AAUP/ CMSTemplates/AcademeTemplates/AcademicArticle.aspx.Retrieved.

Lubbe, S., Worrall, L., \& Klopper, R. (2005). Challenges in postgraduate research: How doctorates come off the rails. Alternation, 12.(1a.) 241-261.

Mouton, J. (2001). How to succeed in your master's and doctoral studies. Pretoria: Van Schaik.

Saint, W. S. (1992). Universities in Africa strategies for stabilization and revitalization. Washington, D. C. World Bank.

Smith, S. W., Brownell, M. T., Simpson, R. L. \& Deshler, D. D. (1993). Successfully completing the dissertation: two reflections on the process. Remedial and Special Education, 14 (3), 53-60.

Spear, R. H. (2000). Supervision of research students: Responding to student expectations. Canberra: The Australian National University. 